\title{
Investigation of Antidiabetic Effect of Ethanolic Extract of Phyllanthus emblica Linn. Fruits in Experimental Animal Models
}

\author{
Zakia Sultana ${ }^{1}$, Md. Safkath Ibne Jami ${ }^{2}$, Md. Ershad $\mathrm{Ali}^{3}$, Mst. Marium Begum ${ }^{1}$, \\ Md. Mominul Haque ${ }^{4^{*}}$ \\ ${ }^{1}$ Department of Pharmacy, University of Rajshahi, Rajshahi, Bangladesh; ${ }^{2}$ Department of Pharmacy, University of Asia Pacific, \\ Dhaka, Bangladesh; ${ }^{3}$ Department of Chemistry, Dhaka College, National University, Dhaka, Bangladesh; ${ }^{4}$ Department of Chemistry \\ and Biomolecular Sciences, Macquarie University, Macquarie Park, Australia. \\ Email: ${ }^{\text {mominul.chem@gmail.com }}$
}

Received October $15^{\text {th }}, 2013$; revised November $18^{\text {th }}, 2013$; accepted November $27^{\text {th }}, 2013$

Copyright (C) 2014 Zakia Sultana et al. This is an open access article distributed under the Creative Commons Attribution License, which permits unrestricted use, distribution, and reproduction in any medium, provided the original work is properly cited. In accordance of the Creative Commons Attribution License all Copyrights (C) 2014 are reserved for SCIRP and the owner of the intellectual property Zakia Sultana et al. All Copyright (C) 2014 are guarded by law and by SCIRP as a guardian.

\section{ABSTRACT}

Hypoglycemic effects were investigated in the ethanolic extract of fruits of Phyllanthus emblica Linn. with long evans rats (100 - 120 g). Residual gut sucrose content, gut perfusion and disaccharidase activity studies were carried out to assess these activities. The residual gut sucrose content study was carried out to reveal the amount of sucrose remaining in the gastro intestinal tract (GIT) at six different segments. The ethanolic fruit extract of Phyllanthus emblica Linn. significantly increases the residual sucrose content throughout the gut after sucrose ingestion. Study on intestinal enzyme activity showed that the extract caused a significant $(p<0.05)$, dose dependent inhibition of intestinal disaccharidase enzyme activity. Evaluation of the effect of the plant extract on intestinal enzyme activity showed significant inhibition of intestinal disaccharidase activity, suggesting that reduction of sucrose absorption may be partly related to the inhibition of disaccharidase activity in the gut. The gut perfusion analysis showed that the extract significantly reduced intestinal glucose absorption. The results of the present study suggest that ethanolic extract of Phyllanthus emblica Linn. has significant antidiabetic effects in a dose dependent manner and this may be effective in the treatment of diabetes.

\section{KEYWORDS}

\section{Phyllanthus emblica; Ethanolic Extract; Antidiabetic Effects; Disaccharidase Activity}

\section{Introduction}

Diabetes mellitus is a major global health concern. In 2000, according to the World Health Organization, at least 171 million people worldwide suffer from diabetes, or $2.8 \%$ of the population. Its incidence is increasing rapidly, and it is estimated that by 2030, this number will almost double [1]. Diabetes mellitus occurs throughout the world, but is more common in the more developed countries. The increase incidence of diabetes in developing countries is due to the trend of urbanization and lifestyle changes, perhaps most importantly a "Western style"

${ }^{*}$ Corresponding author. diet. The prevalence of diabetes mellitus increases with age, and the numbers of older persons with diabetes are expected to grow as the elderly population increases in number. The National Health and Nutrition Examination Survey (NHANES III) demonstrated that, in the population over 65 years old, $18 \%$ to $20 \%$ have diabetes, with $40 \%$ having either diabetes or its precursor form of impaired glucose tolerance.

Diabetes mellitus is characterized by chronic hyperglycemia and postprandial hyperglycemia, both leading to enhanced micro- and macro-vascular morbidity and overall mortality. Diabetes mellitus is a condition in which a person has a high blood sugar (glucose) level as a result 
of the body either not producing enough insulin, or because body cells do not properly respond to the insulin that is produced. Insulin is a hormone produced in the pancreas which enables body cells to absorb glucose, to turn into energy. If the body cells do not absorb the glucose, the glucose accumulates in the blood (hyperglycemia), leading to various potential medical complications.

In traditional practice, medicinal plants are used in many countries to control diabetes mellitus. The hypoglycemic action of these medicinal plants is being studied extensively [2]. Plant drugs are frequently considered to be less toxic and free from side effects than synthetic ones [3]. In the traditional system of Indian medicine plant formulation and in several cases, combined extracts of plants are used as the drug of choice rather than individual. Many of these have shown promising effects [4]). Various herbal formulations like D-400 [5], Trasina [6] are well-known for their antidiabetic effects. Cogent db, a novel and unique herbal drug for diabetes mellitus, contains the extracts of nine medicinal plants. Some of these are known to possess antidiabetic effects and have been used in indigenous systems of medicine to treat diabetes mellitus [7].

Plants have formed the basis for the treatment of diseases in traditional medicine systems for thousands of years, and continue to play a major role in the primary health care of about $80 \%$ of the world's inhabitants [8]. It is estimated that $66 \%$ - $80 \%$ of medicines used in developing countries are based on plants and $80 \%$ of the world's population relies on traditional medicines $[9,10]$. Many of the currently available drugs have been derived directly or indirectly from plants. Within developed countries $25 \%$ of medicinal therapies contain active principles derived from plants [11]. Besides providing active raw materials, plants can offer molecules that serve as templates for the development of new drugs. World ethnobotanical information about medicinal plants reports that almost 800 plants could be used to control diabetes mellitus $[12,13]$. Over the last two decades, several comprehensive reviews [14-20] have been written on the evidence that higher plants are of use in the treatment of diabetes, providing discussions of the botany, phytochemistry, pharmacology, and in some cases, toxicology, of the botanical agents. Literally hundreds of extracts of higher plants used in folk medicine for diabetes (or active principles derived from these plants) have been screened for their biologic activity in both in vitro and in vivo assays. The most extensive review [15] evaluated available data on more than 1000 species of plants reported to have been used to treat diabetes and/or been investigated for antidiabetic activity, and indicated that approximate $80 \%$ of the traditional plants used for the treatment of diabetes demonstrated some antidiabetic activity. In many in- stances the chemical constituent in the plant responsible for the biological activity has been isolated and identified, and information is also available concerning the mechanism of action. Galega officinalis (goat's rue) is used in Europe as a treatment for diabetes since medieval times, which yields a hypoglycemic principle rich in guanidine [21]. Further derivatives of this principle have given rise to biguanides and the present anti-diabetic agent metformin [22].

Prior to the discovery of insulin in 1992 and the later development of oral hypoglycemic agents, the major form of treatment of diabetes mellitus involved dietary manipulation and the use of plant therapies. The recommended use of plants dates back to the Ebers papyrus of around $1550 \mathrm{BC}$. More than 400 plants world-wide have been documented for the treatment of diabetes and the majority await proper scientific and medical evaluation [11]. Most of these traditional medicines are prepared from herbs, spices and plants, which do not form part of the normal diet [11,14]. However, several common components of the diet are traditionally recommended for regular consumption, and some are additionally taken as infusions, decoctions or alcoholic extracts. The World Health Organization has recommended accordingly those traditional plant treatments for diabetes warrant further evaluation. With few exceptions, traditional plant treatments for diabetes have not claimed to be alternatives to insulin therapy in type 1 . Isolated reports have described plant-derived materials that exert an insulin-like effect in type-1 diabetes [23]. However these reports have not been independently evaluated, and there is no evidence that they could provide a long-term botanical substitute for insulin. A small number of review articles exist which document hypoglycemic agents derived from plant treatments for diabetes $[16,24,25]$. Many traditional plant treatments owe their folklore reputation, at least in part, to the presence of polysaccharides, which achieve beneficial effects through reduction of gastrointestinal processing and post-prandial hyperglycemia. However for the majority of traditional plant treatments the active principles present together with their mode of action have yet to be realized [11,12]. Hypoglycemic compounds from plants that help directly combat insulin resistance and/or promote endogenous insulin release are realistic possibilities.

The present study was designed to evaluate the antidiabetic efficacy of ethanolic extract of Phyllanthus emblica Linn. fruits.

\section{Methods and Materials}

\subsection{Collection and Identification of the Plant Materials}

Fresh fruits of Phyllantus emblica Linn. were used in this 
experiments. These were collected from local market and were identified by Bangladesh National Herbarium. The fully dried fruit parts were then grinded to make them powder by grinder. The powder was stored within zipper bag in a refrigerator at $+4^{\circ} \mathrm{C}$ for one month.

\subsection{Preparation of Ethanolic Extract of Phyllanthus emblica Linn. Fruits}

About $415.76 \mathrm{~g}$ of powered material was taken in a clean, flat-bottomed glass container and soaked in $1300 \mathrm{ml}$ of $80 \%$ Ethanol. The container with its contents was sealed and kept for a period of 2 days accompanying occasional shaking and stirring. The whole mixture then underwent a coarse filtration by a piece of clean, white cotton material and then filtered by filter paper. The filtrate (Ethanol extract) obtained was evaporated by Rotary evaporator at 5 to $6 \mathrm{rpm}$ and at $68^{\circ} \mathrm{C}$ temperature. The gummy concentrate was designated as crude extract or ethanolic extract. Then the crude ethanolic extract was dried by freeze drier and preserved at $+4^{\circ} \mathrm{C}$ for one month.

\subsection{Chemicals and Reagents}

Sodium chloride $(\mathrm{NaCl})$, sodium dihydrogen orthophosphate $\left(\mathrm{NaH}_{2} \mathrm{PO}_{4}\right)$, D-glucose, potassium chloride $(\mathrm{KCl})$, sodium bicarbonate $\left(\mathrm{NaHCO}_{3}\right)$, potassium dihydrogen phosphate $\left(\mathrm{KH}_{2} \mathrm{PO}_{4}\right)$, calcium chloride hexahydrate $\left(\mathrm{CaCl}_{2} \cdot 7 \mathrm{H}_{2} \mathrm{O}\right)$, dimethylsulphoxide (DMSO), magnesium sulphate $\left(\mathrm{MgSO}_{4}\right)$, hydrochloric acid $(\mathrm{HCl})$, sodium hydroxide $(\mathrm{NaOH})$ and acetic acid (glacial) were obtained from BDH Chemicals Ltd (Poole, Dorset, UK). The DC protein Kit was procured from Bio-Rad, USA. ADP from Chrono Log Corporation (USA). Commercial kits were used for the determination of glucose, fructosamine, cholesterol and triglyceride from Boehringer Mannheim $\mathrm{GmbH}$.

\subsection{Experimental Animals}

Long Evans male rats $(110 \pm 15$ g) were selected for the present study and acclimatized under standard conditions. The animals were housed under standard laboratory conditions (relative humidity 55\% - 65\%, room temperature $25^{\circ} \mathrm{C} \pm 2^{\circ} \mathrm{C}$, and alternate light-dark cycle of 12 hours each) and were allowed free access to standard dry pellet diet and filtered water. The animals were maintained in the laboratory and the treatment was schedule. Prior to commencement of the experiments, all the rats were acclimatized to the new environmental condition for a period of one week. Animal described as fasted were deprived of food for at least $12 \mathrm{~h}$ but allowed free access to drinking water prior to each experiment. Within 36 Long Evans male rats, 8 rats were randomly assigned into con- trol and extract treated group, 4 rats in each group for determination of residual gut sucrose content. Another 20 rats were randomly assigned into 5 different groups, control, Phyllanthus emblica (0.5 mg/ml), Phyllanthus emblica $(1.0 \mathrm{mg} / \mathrm{ml})$, Phyllanthus emblica $(2.0 \mathrm{mg} / \mathrm{ml})$ and Phyllanthus emblica $(5.0 \mathrm{mg} / \mathrm{ml}), 4$ rats in each group, for determination of intestinal disaccharidase enzyme activity. For determination of intestinal glucose absorption by gut perfusion, a total number of 8 rats were assigned into 2 groups, control and Phyllanthus emblica extract $(1.25 \mathrm{~g} / \mathrm{kg} \mathrm{BW})$ treated group, 4 rats in each group.

\subsection{Determination of Residual Gut Sucrose Content}

Sucrose solution ( $2.5 \mathrm{~g} / \mathrm{kg}$ body weight) with and without extract $(0.5 \mathrm{~g} / \mathrm{kg})$ was fed to the twenty hours fasted rats. Blood samples were obtained from the tail tip before and 30, 60, 120 and 240 min after sucrose administration. Some of the rats were sacrificed before as well as 30, 60, 120 and 240 min after sucrose loading. The gastrointestinal tract was excised and divided into 6 segments: the stomach, the upper $20 \mathrm{~cm}$, middle, and lower $20 \mathrm{~cm}$ of the small intestine, the cecum, and the large intestine. Different segments of gastrointestinal tract of sacrificed animals were washed and acidified with $\mathrm{H}_{2} \mathrm{SO}_{4}$ and centrifuged at $3000 \mathrm{rpm}$ for $10 \mathrm{~min}$. The blood glucose level and the amount of glucose liberated from residual sucrose in the gastrointestinal tract were measured from supernatant. Then the gastrointestinal sucrose content was calculated from the amount of liberated glucose by glucose-oxidase (GOD-PAP) method using commercial kit.

\subsection{Determination of Intestinal Disaccharidase Activity (Enzyme Activity)}

Different dose of plant extracts $(0.5,1.0,2.0$ and 5.0 $\mathrm{mg} / \mathrm{ml}$ ) were administration orally to four different groups (each group contains four rats) of $20 \mathrm{~h}$ fasted rats. Control group was administered equal volume of water. One hour following administration, the small intestine between the part just below the duodenum and the part just above the cecum was isolated and cut longitudinally and homogenized with $10 \mathrm{ml}$ of saline. The homogenate (20 ml) was then incubated with $40 \mathrm{mM}$ sucrose at $37^{\circ} \mathrm{C}$ for $1 \mathrm{~h}$. After centrifugation at $3000 \mathrm{rpm}$ for $10 \mathrm{~min}$, the supernatant was used as crude enzyme solution. The activities of intestinal disaccharidase were measured by determination of glucose released from sucrose. The converted glucose in the solution was estimated by glucose-oxidase (GOD-PAP) method using commercial kit and protein content of the homogenate was determined 
using DC protein kit. Disaccharidase activity was calculated by glucose concentration converted from sucrose as $\mu \mathrm{mol} / \mathrm{mg}$ protein $/ \mathrm{h}$.

\subsection{Determination of Intestinal Glucose Absorption by Gut Perfusion}

An intestinal perfusion technique was used to study the effect of the plant materials on intestinal absorption of glucose in rats fasted for 36 hours and anesthetized with sodium pentobarbital. The plant materials $(1.25 \mathrm{~g} / \mathrm{kg}$ body weight) suspended in Kreb's solution supplemented with glucose $(65.0 \mathrm{gm} / \mathrm{l})$ was passed through upper part of duodenum (just after stomach) and the perfusate was collected from a catheter set at the end of ileum. The control group was perfused only Kreb supplemented with glucose. The results were expressed as percentage of absorbed glucose, calculated from the amount of glucose in solution before and after the perfusion.

\subsection{Statistical Analysis of Data}

The statistical analysis was carried by one way Analysis of variance test (ANOVA) to compare the effects on treatment groups before and after treatment with control group. p values $<0.05$ (95\% confidence limit) was considered statistically significant, using software SPSS. The null hypothesis $\left(\mathrm{H}_{0}\right)$ was assumed that there was no difference in effects of treatments between the treatment groups compared with control group and alternate hypothesis $\left(\mathrm{H}_{1}\right)$ was assumed there was significant difference in effect of treatment between the treatment groups compared with control group.

\section{Results}

\subsection{Determination of Residual Gut Sucrose Content}

The Residual gut sucrose content study carried out to reveal the amount of sucrose remaining in the gastro intestinal tract (GIT) at six different segments after administration of fixed amount of sucrose solution $(2.5 \mathrm{~g} / \mathrm{kg}$ body weight). The results of the residual gut sucrose content study of GIT showed that total sucrose remaining in the gut in control rats (not treated with extract) were 38.6, 18.2, 18, and $12.2 \mathrm{mg} / \mathrm{ml}$ at 30, 60, 180 and 360 minutes respectively. Whereas, total sucrose remaining in the gut after administration of extract $(0.5 \mathrm{~g} / \mathrm{kg}$ body weight) at 30, 60, 180 and 360 minutes was 75.5, 34.5, 34, and $22.4 \mathrm{mg} / \mathrm{ml}$ respectively (Figure 1). Thus ethanolic fruit extract of Phyllanthus emblica Linn. greatly increases the amount of sucrose remaining in the GIT after sucrose administration. As a consequence the fruit extract of Phyllanthus emblica Linn. significantly suppressed postprandial hyperglycemia after sucrose ingestion. The changes of sucrose content at six different segment of GIT after ingestion of sucrose solution (2.5 $\mathrm{g} / \mathrm{kg}$ body weight) in control and Phyllanthus emblica Linn. fruits extract $(0.5 \mathrm{~g} / \mathrm{kg}$ body weight) treated rats were given in Table 1.

\subsection{Determination of Intestinal Disaccharidase Enzyme Activity}

Study on intestinal enzyme activity showed that the extract caused a significant $(\mathrm{p}<0.05)$, dose dependent inhibition of intestinal disaccharidase enzyme activity,

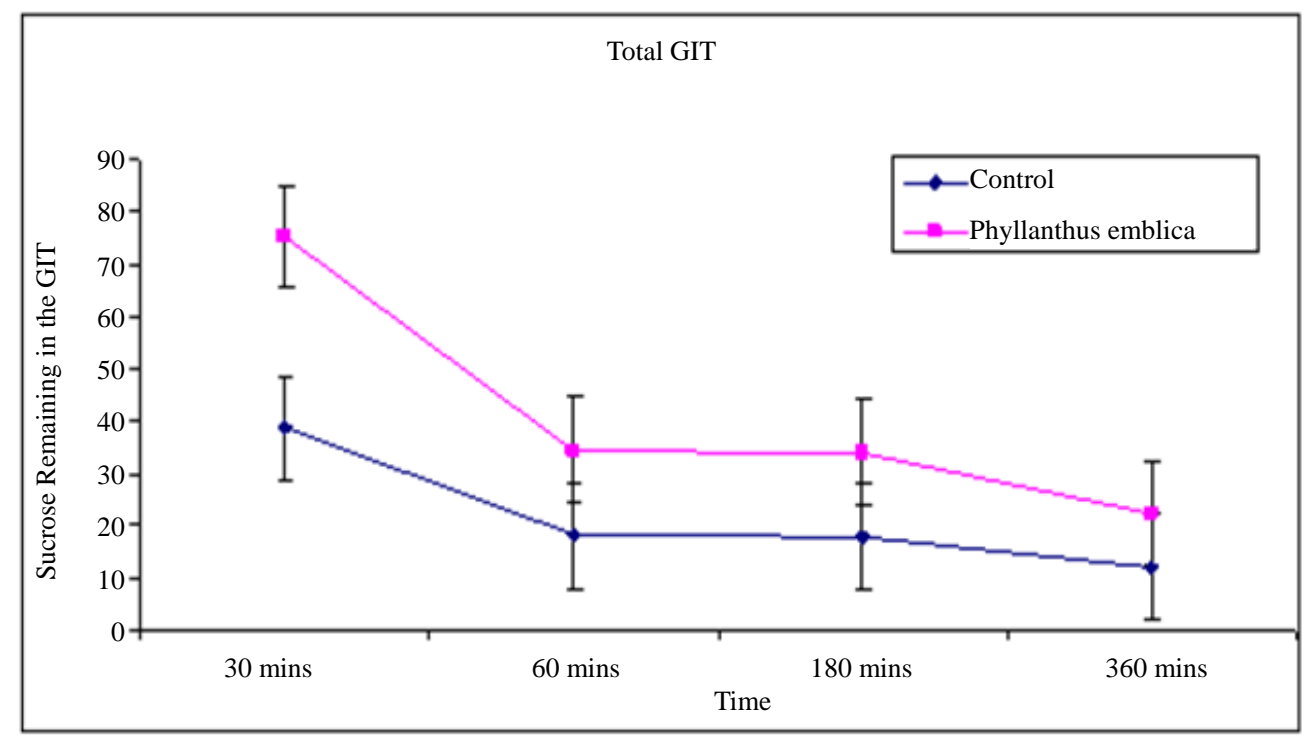

Figure 1. Total sucrose remaining in the GIT $(\mathrm{mg} / \mathrm{ml})$ after sucrose ingestion in control and Phyllanthus emblica Linn. fruits extract treated rats. 
Table 1. Changes of sucrose content at six different segment of GIT (mg/ml) in control and Phyllanthus emblica Linn. extract treated rats (data were expressed as mean $\pm \mathrm{SD} .^{\mathrm{a}}=\mathbf{p}<0.05$ compared to non-diabetic control rats).

\begin{tabular}{|c|c|c|c|c|c|}
\hline Group & Segments & 30 minutes & 60 minutes & 180 minutes & 360 minutes \\
\hline \multirow{8}{*}{ Control group } & Stomach & $11.1 \pm 2.04$ & $2.1 \pm 1.21$ & $2.1 \pm 1.16$ & $2.3 \pm 1.22$ \\
\hline & Middle Small Intestine & $6.5 \pm 1.62$ & $2.2 \pm 1.32$ & $3.3 \pm 1.22$ & $1.3 \pm 0.51$ \\
\hline & Lower Small Intestine & $3.6 \pm 1.21$ & $2.3 \pm 1.25$ & $3.2 \pm 1.23$ & $1.5 \pm 0.62$ \\
\hline & Caecum & $1.9 \pm 0.86$ & $1.9 \pm 0.83$ & $2.0 \pm 0.98$ & $2.0 \pm 0.98$ \\
\hline & Large & $1.7 \pm 0.32$ & $3.0 \pm 1.62$ & $1.5 \pm 0.62$ & $0.8 \pm 0.22$ \\
\hline & Total sucrose remaining in the gut & 38.6 & 18.2 & 18 & 12.2 \\
\hline & Stomach & $12.3 \pm 2.35$ & $5.8 \pm 1.61^{\mathrm{a}}$ & $1.6 \pm 0.48$ & $1.2 \pm 0.46$ \\
\hline & Middle Small Intestine & $40.6 \pm 3.62^{\mathrm{a}}$ & $6.22 \pm 1.86^{\mathrm{a}}$ & $2.3 \pm 0.79$ & $1.8 \pm 0.88$ \\
\hline \multirow[t]{4}{*}{ Treatment group ( 0.5 g/kg body weight) } & Lower Small Intestine & $1.9 \pm 0.86$ & $4.0 \pm 1.49^{\mathrm{a}}$ & $1.6 \pm 0.47$ & $1.5 \pm 0.61$ \\
\hline & Caecum & $1.6 \pm 0.123$ & $1.6 \pm 1.36^{\mathrm{a}}$ & $2.0 \pm 0.76$ & $1.3 \pm 0.51$ \\
\hline & Large & $1.4 \pm 0.09$ & $2.1 \pm 1.18$ & $2.6 \pm 0.82$ & $1.2 \pm 0.48$ \\
\hline & Total sucrose remaining in the gut & 75.5 & 34.5 & 34 & 22.4 \\
\hline
\end{tabular}

measured by determination of glucose released from sucrose. Disaccharidase activity was calculated by glucose concentration converted from sucrose as $\mu \mathrm{mol} / \mathrm{mg}$ protein/h. The disaccharidase enzyme activity of $0.5 \mathrm{mg}, 1.0$ mg, $2.0 \mathrm{mg}$ and $5.0 \mathrm{mg}$ per ml Phyllanthus emblica Linn. extract treated rats were 0.043, 0.027, 0.025, 0.020 $\mu \mathrm{mol} / \mathrm{mg}$ protein/h respectively compared with 0.0643 $\mu \mathrm{mol} / \mathrm{mg}$ protein/h in control rats (Table 2). Evaluation of the effect of the plant extract on intestinal enzyme activity showed significant inhibition of intestinal disaccharidase activity, which suggests that reduction of sucrose absorption may be partly related to the inhibition of disaccharidase activity in the gut.

\subsection{Determination of Intestinal Glucose Absorption by Gut Perfusion}

In the gut-perfusion study the percentage of glucose absorbed were measured in control rats and Phyllanthus emblica extract treated $(1.25 \mathrm{~g} / \mathrm{kg}$ body weight) rats at 6 different time after administration, calculated from the amount of glucose in solution before and after administration. The experimental data (Table 3) showed that the percentage of glucose absorbed by control rats were 60.30, 64.07, 63.02, 61.05, 60.25 and 59.57 percent at 5, 10, 15, 20, 25 and 30 minutes respectively. Whereas, the percentage of glucose absorbed by and Phyllanthus emblica extract treated rats at 5, 10, 15, 20, 25 and $30 \mathrm{mi}-$ nutes were 29.75, 28.38, 27.25, 25.25, 23.63, and 22.63
Table 2. Intestinal disaccharidase enzyme activity ( $\mu \mathrm{mol} / \mathrm{mg}$ protein/h) in control and Phyllanthus emblica Linn. extract treated rats (data were expressed as mean \pm SD. ${ }^{*}$ p $<0.05$ compared to non-diabetic control rats).

\begin{tabular}{cc}
\hline Treatment group & $\begin{array}{c}\text { Disaccharidase activity } \\
(\mu \mathrm{mol} / \mathrm{mg} \text { protein/h) Mean } \pm \mathrm{SD}\end{array}$ \\
\hline $\begin{array}{c}\text { Control } \\
\text { Phyllanthus emblica } \\
(0.5 \mathrm{mg} / \mathrm{ml})\end{array}$ & $0.0643 \pm 0.0009$ \\
$\begin{array}{c}\text { Phyllanthus emblica } \\
(1.0 \mathrm{mg} / \mathrm{ml})\end{array}$ \\
$\begin{array}{c}\text { Phyllanthus emblica } \\
(2.0 \mathrm{mg} / \mathrm{ml}) \\
\text { Phyllanthus emblica } \\
(5.0 \mathrm{mg} / \mathrm{ml})\end{array}$ & $0.0430 \pm 0.0005^{*}$ \\
\hline
\end{tabular}

Table 3. Percentage (\%) of glucose absorbed from gut in control and Phyllanthus emblica Linn. extract $(1.25 \mathrm{~g} / \mathrm{kg}$ body weight) treated rats (data were expressed as mean \pm SD. ${ }^{*}$ p $<0.05$ compared to non-diabetic control rats).

\begin{tabular}{ccc}
\hline $\begin{array}{c}\text { Time of experiment } \\
\text { (minutes after treatment) }\end{array}$ & Control & $\begin{array}{c}\text { Phyllanthus emblica } \\
(1.25 \mathrm{~g} / \mathrm{kg} \mathrm{BW})\end{array}$ \\
\hline 5 minutes & $60.30 \pm 0.91$ & $29.75 \pm 0.83^{*}$ \\
10 minutes & $64.07 \pm 0.83$ & $28.38 \pm 0.83^{*}$ \\
15 minutes & $63.02 \pm 0.76$ & $27.25 \pm 1.16^{*}$ \\
20 minutes & $61.50 \pm 0.82$ & $25.25 \pm 0.97^{*}$ \\
25 minutes & $60.25 \pm 0.78$ & $23.63 \pm 1.05^{*}$ \\
30 minutes & $59.57 \pm 0.67$ & $22.63 \pm 1.20^{*}$ \\
\hline
\end{tabular}


percent respectively. These results showed that the intestinal glucose content of Phyllanthus emblica Linn. extract treated group is much lower than the control group. Thus gut perfusion analysis suggested that the extract significantly reduced intestinal glucose absorption.

\section{Discussion}

The prevalence of diabetes is rising relentlessly around the world. Current estimates suggest that, the world prevalence of diabetes among adults (aged 20 - 79 years) will be 6.4\%, affecting 285 million adults, in 2010, and will increase to $7.7 \%$ and 439 million adults by 2030 . Between 2010 and 2030, there will be a 69\% increase in numbers of adults with diabetes in developing countries and a $20 \%$ increase in developed countries [26]. However, Amos et al. reported in 1997 that the number of persons with diabetes will rise from 151 million in the year 2000, to 221 million by the year 2010, and to 300 million by 2025 [27]. This rise is predicted to occur in virtually every nation, with the greatest increases expected in developing countries. Regions with greatest potential are Asia and Africa, where the rate of diabetes will be rose to 2- to 3-fold to the next 10 years compared with the present rates. This explosive increase in the prevalence of diabetes and the consequences of its complications and associated disorders represents the greatest health care challenge facing the world today [28]. Reasons for this rise include increase in sedentary lifestyle, consumption of energy rich diet, obesity and higher life span [29]. Though biguanides and sulfonylureas are valuable in the treatment of diabetes mellitus, their use is restricted by their limited action, pharmacokinetic properties, secondary failure rates and accompanying side effects [14]. Moreover, these therapies only partially compensate for metabolic derangements seen in diabetes and do not necessarily correct the fundamental biochemical lesion [30]. As the incidence of diabetes increases rapidly across the globe there is an urgent need to expand the range of effective palliatives available to sufferers.

Nature has been a source of medicinal treatments for thousands of years, and plants-based systems continue to play an essential role in the primary health care of $80 \%$ of the world's underdeveloped and developing countries [27]. Biguanides developed from a prototypic plant molecule is an excellent example of anti-diabetic drug development from plants. Thus, it is prudent in the current context to look for new and if possible more efficacious hits from the vast reserves of phytotherapy. Many herbal medicines have been recommended for the treatment of diabetes. On the other hand, as indicated not all of the plants reported to be useful are entirely safe, and they emphasize the need for carefully planned scientific re- search to identify those hypoglycemic plants with true therapeutic efficacy and safety [15].

Renewed attention in alternative medicines and natural therapies has led to a revived interest in the use of traditional plants for the treatment of diabetes. In this regard the screening of plant materials for hypoglycemic properties is important as it might provide a new lead(s) as antidiabetic agent(s). Phyllanthus emblica Linn. has been using as an antidiabetic agent for a long time. Efficacy of this plant in the treatment of diabetes has been studied in details. In the present study, this plant was selected to explore the mechanism of action in Long Evans rat.

In previous studies it has been found that Phyllanthus emblica Linn. helps in total control of diabetes. In the present study we were explored the extra pancreatic action of the plant in Long Evans rats. It has been demonstrated that the post-prandial hyperglycemia is an important cardiovascular risk factors in type 2 diabetic patients [31]. Studies have shown that the post-meal hyperglycemia can be associated with 2-fold rise of the risk of heart disease and fatal cardiovascular diseases [32]. In acute test the extract opposed the rise of blood glucose when fed with simultaneous glucose load. Significant antihyperglycemic activity when given with a simultaneous glucose load in non-diabetic rats indicates that the extract may interfere with the intestinal glucose absorption in the gut.

One of the objectives of the present study was to investigate whether the anti-hyperglycemic effect is related to the inhibition of carbohydrate absorption in the gut. In order to confirm this hypothesis, we examined sucrose content in six segments of the rat's gastrointestinal tract after simultaneous administration of sucrose. Ethanolic extract of Phyllanthus emblica Linn. significantly suppressed postprandial hyperglycemia after sucrose ingestion. The extract increased the residual sucrose content throughout the gut at $2 \mathrm{~h}$ after sucrose administration. However no sucrose was detected in the large intestine at this time indicating that all sucrose was absorbed. This result suggests that the extract can delay sucrose absorption without suppressing it which might be due to inhibition of rapid digestion and absorption of carbohydrate at the upper part of intestine and undigested carbohydrate is digested and absorbed beyond the upper part completely before reaching the large intestine. These findings also suggest that the reduction of hyperglycemia by the extract is, at least partly, related to the retardation of carbohydrate absorption in the gut. This was also confirmed in gut perfusion experiment with glucose where the extract significantly reduced intestinal glucose absorption. Evaluation of the effect of the plant extract on intestinal enzyme activity showed significant inhibition of intestinal disaccharidase activity, which suggests that reduction 
of sucrose absorption may be partly related to the inhibition of disaccharidase activity in the gut.

\section{Conclusion}

The rapidly increasing prevalence of diabetes mellitus throughout the world will continue to challenge the existing therapies and encourage new approaches to counter diabetes mellitus. The present study has evaluated potential antidiabetic activity of Phyllanthus emblica plants, traditionally used in the treatment of diabetes mellitus. The experiments carried out in this study showed positive hypoglycemic activity of the plant. However, this is a preliminary study and hopefully this will provide a lead to carry out further investigation to assess whether or not Phyllanthus emblica extracts may be used commercially or not.

\section{REFERENCES}

[1] S. Wild, G. Roglic, A. Green, R. Sicree and H. King, "Global Prevalence of Diabetes: Estimates for the Year 2000 and Projections for 2030," Diabetes Care, Vol. 27, No. 5, 2004, pp. 1047-1053. http://dx.doi.org/10.2337/diacare.27.5.1047

[2] F. J. Alarcon-Aguilar, E. Hernandez-Galicia, A. E. Campos-Sepulveda, S. Xolalpa-Molina, G. F. Rivas-Vilchis, L. I. Vazquez-Carrillo and R. Roman-Ramos, "Evaluation of the Hypoglycemic Effect of Cucurbita ficifolia Bouché (Cucurbitaceae) in Different Experimental Models," Journal of Ethnopharmacology, Vol. 82, No. 2-3, 2002, pp. 185-189.

http://dx.doi.org/10.1016/S0378-8741(02)00176-9

[3] L. Pari and J. Umamaheswari, "Antihyperglycaemic Activity of Musa sapientum Flowers: Effect on Lipid Peroxidation in Alloxan Diabetic Rats," Phytotherapy Research, Vol. 14, No. 2, 2000, pp. 136-138. http://dx.doi.org/10.1002/(SICI)1099-1573(200003)14:2< 136::AID-PTR607>3.0.CO;2-K

[4] S. Umamaheswari, D. J. Leena, J. Srikanth, R. Lavanya, D. Chamundeeswari and C. R. Uma Maheswara, "Antidiabetic Activity of a Polyherbal Formulation (DIABET)," International Journal of Pharmaceutical Sciences, Vol. 2, No. 1, 2010, pp. 18-22.

[5] S. K. Mitra, S. Gopumadhan and T. S. Muralidhar, "Effect of D-400, an Ayurvedc Herbal Formulation on Experimentally Induced Diabetic Mellitus," Phytotherapy Research, Vol. 10, No. 5, 1996, pp. 433-435. http://dx.doi.org/10.1002/(SICI)1099-1573(199608)10:5< 433::AID-PTR864>3.0.CO;2-D

[6] K. Bhattacharya, S. K. Satyan and A. A. Chakrabrati, "Effect of Trasina, an Ayurvedic Herbal Formulation, on Pancreatic Islet Superoxide Dismutase Activity in Hyperglycaemic Rats,” Indian Journal of Experimental Biology, Vol. 35, No. 3, 1997, pp. 297-299.

[7] L. PariL and G. Saravanan, “Antidiabetic Effect of Cogent db, a Herbal Drug in Alloxan-Induced Diabetes Mel- litus," Comparative Biochemistry and Physiology Part C: Toxicology \& Pharmacology, Vol. 131, No. 1, 2002, pp. 19-25. http://dx.doi.org/10.1016/S1532-0456(01)00259-9

[8] N. R. Farnsworth, O. Akerele, A. S. Bingel, D. D. Soejarto and Z. Guo, "Medicinal Plants Therapy," Bulletin of the World Health Organization, Vol. 63, No. 6, 1985, pp. 965-981.

[9] D. S. Fabricant and N. R. Farnsworth "The Value of Plants Used in Traditional Medicine for Drug Discovery,” Environmental Health Perspectives, Vol. 109, No. 1, 2001, pp. 69-75.

[10] P. B. Weragoda, "Some Questions about the Future of Traditional Medicine in Developing Countries,” Journal of Ethnopharmacology, Vol. 2, No. 2, 1980, pp. 193-194. http://dx.doi.org/10.1016/0378-8741(80)90015-X

[11] M. O. Ojezele and O. M. Abatan, "Hypoglycaemic and Coronary Risk Index Lowering Effects of Bauhinia Thoningii in Alloxan Induced Diabetic Rats,” African Health Sciences, Vol. 11, No. 1, 2011, pp. 85-89.

[12] M. Wais, I. Nazish, A. Samad, S. Beg, S. Abusufyan, S. A. Ajaj and M. Aqil, "Herbal Drugs for Diabetic Treatment: An Updated Review of Patents," Recent Patents on Anti-Infective Drug Discovery, Vol. 7, No. 1, 2012, pp. 53-59. http://dx.doi.org/10.2174/157489112799829701

[13] R. Udayakumar, S. Kasthurirengan, T. S. Mariashibu, M. Rajesh, V. R. Anbazhagan, S. C. Kim, A. Ganapathi and W. C. Choi, "Hypoglycaemic and Hypolipidaemic Effects of Withania Somnifera Root and Leaf Extracts on Alloxan-Induced Diabetic Rats," International Journal of Molecular Sciences, Vol. 10, No. 5, 2009, pp. 2367-2382. http://dx.doi.org/10.3390/ijms10052367

[14] C. J. Bailey and C. Day, "Traditional Plant Medicines as Treatments for Diabetes,” Diabetes Care, Vol. 12, No. 8, 1989, pp. 553-564.

http://dx.doi.org/10.2337/diacare.12.8.553

[15] R. J. Marles and N. R. Farnsworth, "Antidiabetic Plants and Their Active Constituents," Phytomedicine, Vol. 2, No. 2, 1995, pp. 137-189. http://dx.doi.org/10.1016/S0944-7113(11)80059-0

[16] B. O. Bever and G. R. Zahand, "Plant with Oral Hypoglycemic Action,” Quarterly Journal of Crude Drug Research, Vol. 17, No. 3-4, 1979, pp. 139-196.

[17] A. B. Padavala, S. Gadde, B. Radha, V. L. Vedurupaka, S. R. Talluru, R. B. Yellapu and S. Kolli, "A Database of 389 Medicinal Plants for Diabetes,” Bioinformation, Vol. 1, No. 4, 2006, pp. 130-131. http://dx.doi.org/10.6026/97320630001130

[18] A. Al-Aboudi and F. U. Afifi, "Plants Used for the Treatment of Diabetes in Jordan: A Review of Scientific Evidence,” Pharmaceutical Biology, Vol. 49, No. 3, 2011, pp. 221-239. http://dx.doi.org/10.3109/13880209.2010.501802

[19] G. B. Kavishankar, N. Lakshmidevi, S. M. Mahadeva, H. S. Prakash and S. R. Niranjana, "Diabetes and Medicinal Plants-A Review," International Journal of Pharmaceutical and Biomedical Sciences, Vol. 2, No. 3, 2011, pp. 65-80. 
[20] S. Elavarasi, K. Saravanan and C. Renuka, “A Systematic Review on Medicinal Plants Used to Treat Diabetes Mellitus,” International Journal of Pharmaceutical, Chemical and Biological Sciences, Vol. 3, No. 3, 2013, pp. 983992.

[21] C. J. Bailey, C. Day, S. L. Turner and B. A. Leatherdale, "Cerasee, a Traditional Treatment for Diabetes: Studies in Normal and Streptozotocin Diabetic Mice,” Diabetes Research, Vol. 2, No. 2, 1985, pp. 81-84.

[22] J. Sterne, "Pharmacology and Mode of Action of the Hypoglycemic Guanidine Derivatives,” In: G. D. Campbell, Ed., Oral Hypoglycemic Agents, New York Academic Press, 1969, pp. 193-245.

[23] P. Khanna, S. C. Jain and A. Panagariya, "Hypoglycemic Activity of Polypeptide-p from a Plant Source," Journal of Natural Products, Vol. 44, No. 6, 1981, pp. 648-655. http://dx.doi.org/10.1021/np50018a002

[24] C. Day, "Hypoglycaemic Compounds from Plants,” In: C. J. Bailey and P. R. Flatt, Eds., New Antidiabetic Drugs, Smith-Gordon, London, 1990, pp. 267-278.

[25] J. A. Duke, "Handbook of Medicinal Herbs," CRC Press, Boca Raton, 1985, pp. 675-280.

[26] J. E. Shaw, R. A. Sicree and P. Z. Zimmet, "Global Estimates of the Prevalence of Diabetes for 2010 and 2030," Diabetes Research and Clinical Practice, Vol. 87, No. 1,
2010, pp. 4-14.

http://dx.doi.org/10.1016/j.diabres.2009.10.007

[27] A. F. Amos, D. J. Mccarty and P. Zimmet, "The Rising Global Burden of Diabetes and Its Cmplications: Estimates and Projections to the Year 2010," Diabetic Medicine, Vol. 14, No. 5, 1997, pp. S1-S85.

[28] P. Zimmet, K. Alberti and J. E. Shaw, "Global and Societal Implications of the Diabetes Epidemic," Nature, Vol. 414, No. 6865, 2001, pp. 782-787. http://dx.doi.org/10.1038/414782a

[29] C. S. Yajnik, "The Insulin Resistance Epidemic in India: Fetal Origins, Later Lifestyle, or Both?” Nutrition Reviews, Vol. 59, No. 1, 2001, pp. 1-9. http://dx.doi.org/10.1111/j.1753-4887.2001.tb01898.x

[30] R. Taylor and L. Agius, "The Biochemistry of Diabetes," Biochemical Journal, Vol. 250, No. 3, 1988, pp. 625-640.

[31] G. Paolisso, M. Barbieri, M. R. Rizzo and D. Manzella, "Prevention of Disability and Quality of Care in Aged Type II Diabetics,” Giornale Di Gerontologia, Vol. 51, No. 5, 2003, pp. 436-439.

[32] E. Barrett-Connor and A. Ferrara, "Isolated Postchallenge Hyperglycemia and the Risk of Fatal Cardiovascular Disease in Older Women and Men: The Rancho Bernardo Study," Diabetes Care, Vol. 21, No. 8, 1998, pp. 12361239. http://dx.doi.org/10.2337/diacare.21.8.1236 